\title{
The Role of Toll-Like Receptors in CNS Rabies Infection
}

Sedigheh Ghasemi ${ }^{1}$, Alireza Gholami ${ }^{2}$, Fatemeh Jahanbakhsh², Maryam Fazeli², Shaghayegh Anvari ${ }^{3}$, Amir Ghaemi2 ${ }^{*}$

${ }^{1}$ Shefa Neuroscience Research Center, Khatam Alanbia Hospital, Tehran, Iran

${ }^{2}$ Department of Virology, Institute Pasteur of Iran, Tehran, Iran

${ }^{3}$ Infectious Diseases Research Center, Department of Microbiology, Golestan University of Medical Sciences, Gorgan, Iran

\section{A BSTRACT}

Introduction: Several investigations revealed that the activation of the innate immune system plays a crucial role in the pathogenesis of numerous diseases. The innate immune system activation occurs in response to pathogens or tissue injury via pattern-recognition receptors that recognize pathogen-associated molecular patterns. The innate immune system triggered by these interactions besides the general responses causes a specific response to pathogen. In addition, this pathogen-specific innate response affects the specificity of the adaptive immune response through directing the differentiation of T-cells into functionally distinct subtypes. Although the mechanism(s) by which different Rabies viruses induce differential immune responses are unknown, recent studies indicate that the consequence of rabies virus infection is dependent upon the rapid stimulation of innate and adaptive immunity. The responses prevent viral entry into the central nervous system (CNS), where it can escape immunity. Laboratory strains that reach the CNS can be cleared and this has obviously happened in individuals with rabies. Thus, during rabies virus infection, pattern-recognition receptors of rabies can be recognized in the periphery and the CNS. Conclusion: To study these possibilities, the consequence of rabies infection in mice lacking adaptor myeloid differentiation factor 88 (MyD88) was demonstrated. Toll-like receptors (TLRs) signals, except for TLR3, activate proinflammatory reaction via the adaptor protein MYD88. Only mice lacking TLR7 displayed a marked mortality compared with MyD88 negative and control mice with deficits in both the development of peripheral immunity and rabies virus clearance from the CNS. The review demonstrated that TLR7 plays a vital role in controlling and directing of immune response against the rabies virus.

\section{Key words:}

1.Rabies virus

2. Central Nervous System

3. Toll-Like Receptors

4. Immunity

\section{* Corresponding Author: Amir Ghaemi}

E-mail: ghaem_amir@yahoo.com 


\title{
نقش كيرندههاى شبه تول در عفونت سيستم عصبى مركزى هارى
}

\author{
صديقه قاسمى'، عليرضا غلامى'، فاطمه جهانبخش'،، مريم فاضلى'، شقايق انورى"، امير قائمى" \\ 'مركز تحقيقات علوم اعصاب شفا، بيمارستان خاتم الانبياء، تهران، ايران \\ rكروه ويروس شناسى، انيستيتو باستور ايران، تهران، ايران

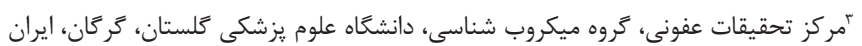

كليد وازمها:

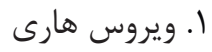

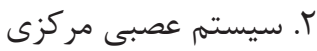

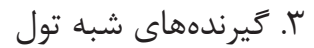

أ. إيمنى
" | (نويسنده مسئول: امير قائمى

آدرس الكترونيكى: ghaem_amir@yahoo.com
مقدمه: مطالعات متعددى نشان دادهاند كه فعالسازى سيستم ايمنى ذاتى نقش مهمئى در بيمارى زيمايى

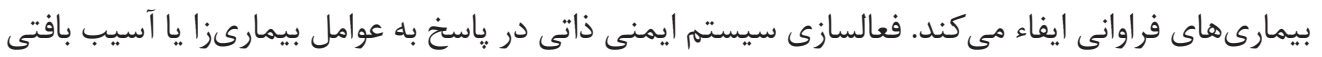

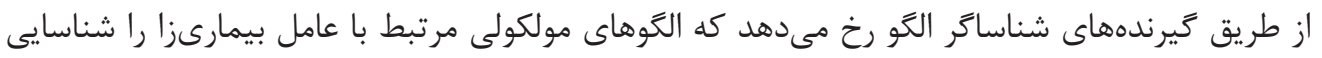

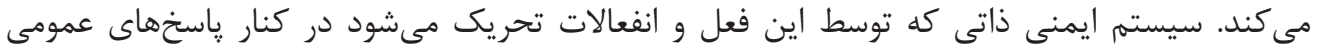

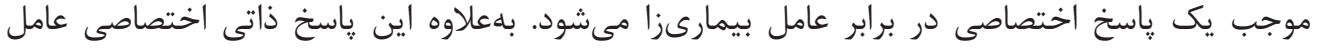

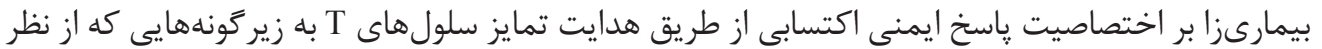

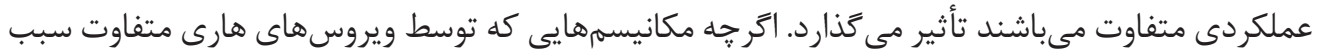

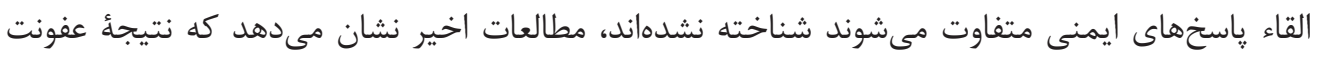

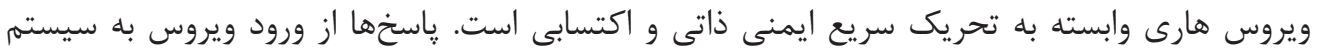

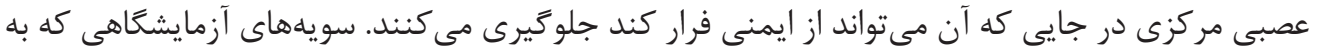

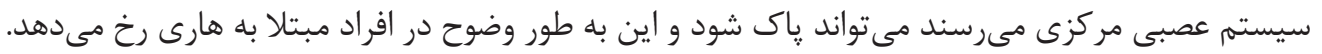

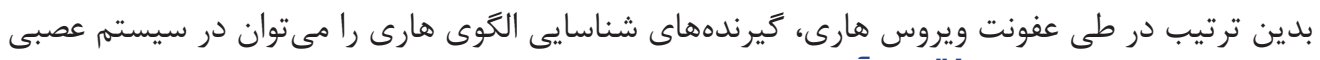

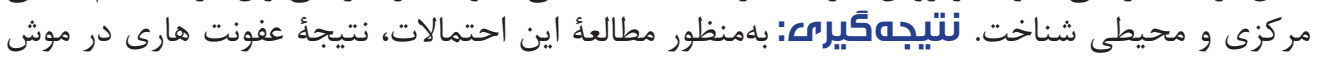

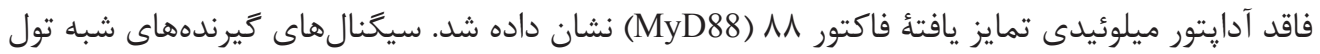

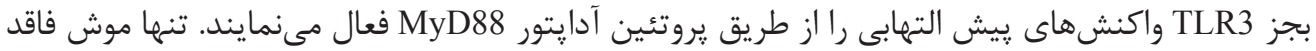

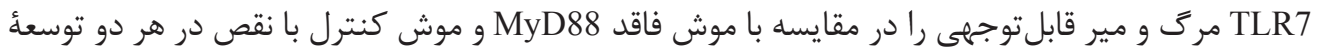

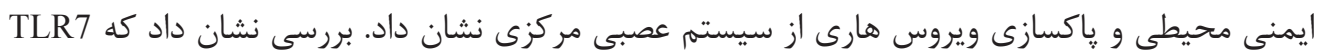

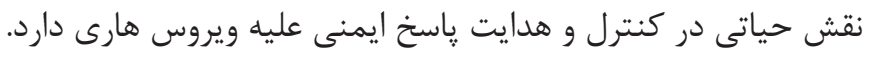




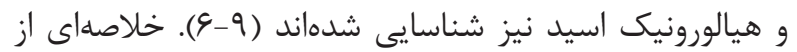

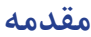

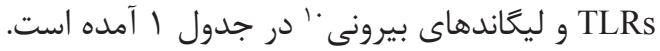
مولكول هاى آدايتور و مسيرهاى داخل سلولى زمانى كه ليعاند به ناحية خارجى گيرندههاى TLR متصل

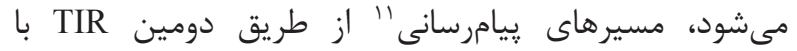

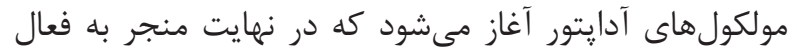

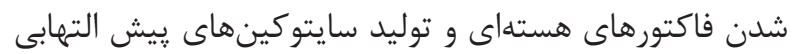
مىشود. مولكولهاى آدايتور شامل: ميلوئيد تمايزيافتئ فاكتور

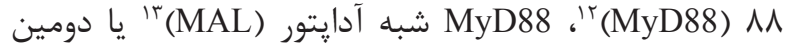

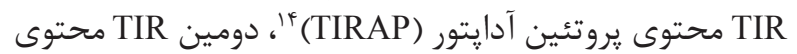
آدايتور القاء كننده اينترفرون بتا (TRIF)

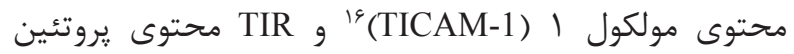

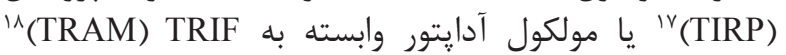

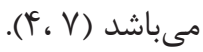

مسير وابسته به MyD88 منجر به فعاليت فاكتورهاى هستهاى NFkB MyD88 و و IL-12 IL-10

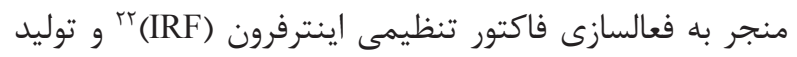

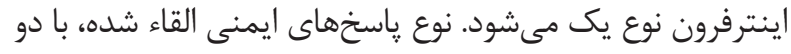

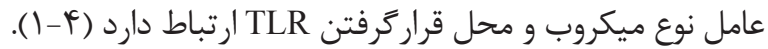
اينترفِرونها عوامل ضد ويروسى قوى هستند؛ به طورى كه آنها

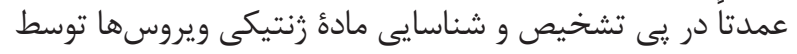

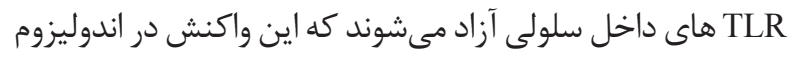

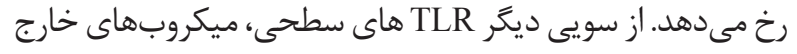

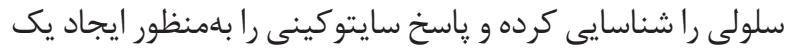

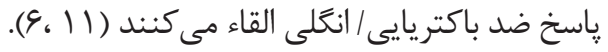
مLىتواند در يك مسير وابسته به TRIF-3

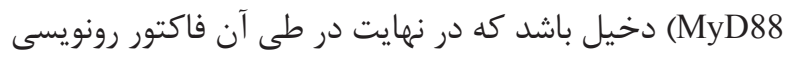

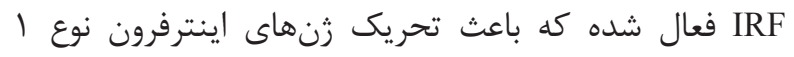
(IFN- $\beta$ و IFN- $\alpha$ ) كد كردن كموكاينهايى مانند مىشود را رمز حذارى مى كند (V، (V) TLR-7 و TLR-9 از مسير MyD88-TRIF استفاده مى كنند

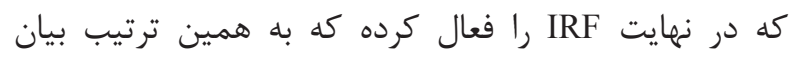

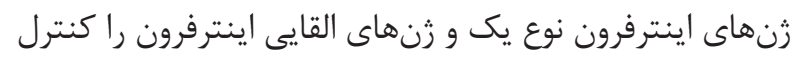

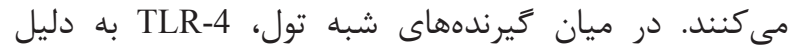
هدايت، سيخنالى منحصر به فرد مى بـاشد. اين خيرنده قادر است نوبه

${ }^{1}$ Toll like receptors

${ }^{2}$ Drosophila melanogaster

${ }^{3}$ Toll receptors

${ }^{4}$ Dendritic cells

${ }^{5}$ Natural killer cell

${ }^{6}$ Regulatory T cell

${ }^{7}$ Interleukin-1

${ }^{8}$ Pathogen-associated molecular patterns

${ }^{9}$ Endogenous

${ }^{10}$ Exogenous

${ }^{11}$ Signaling

${ }^{12}$ Myeloid differentiation primary response gene 88

${ }^{13}$ MyD88-adapter-like

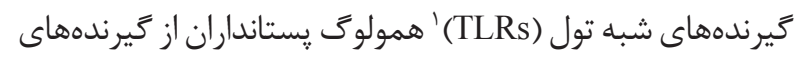

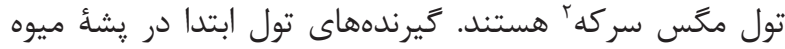

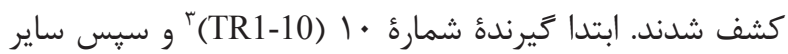

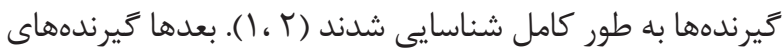

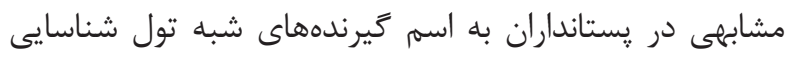

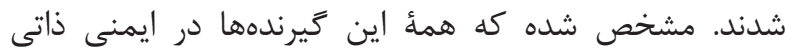

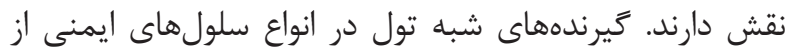

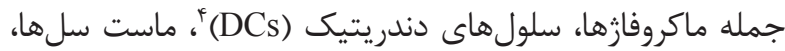

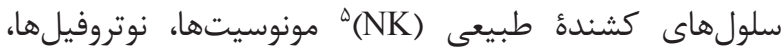

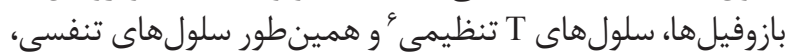
رودهاى، ايى تليال و اندوتليال وجود دارند آندئ.

تاكنون 1 ا گيرنده شبه تول در ريستانداران شناسايى شده است.

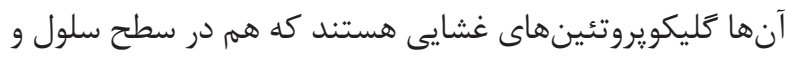

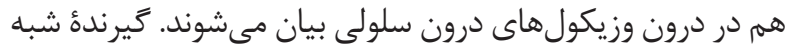

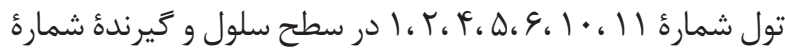

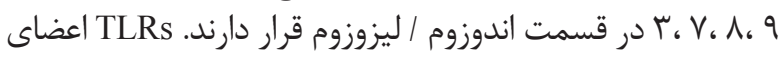

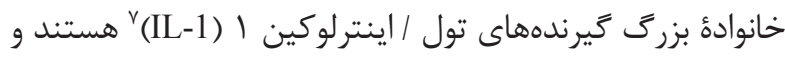

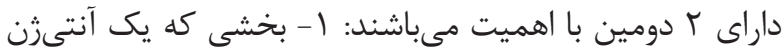

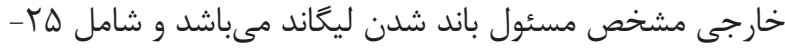

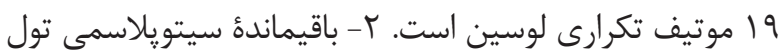

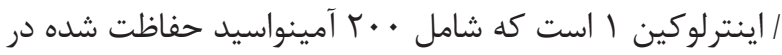

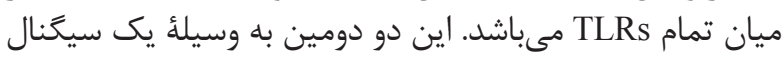

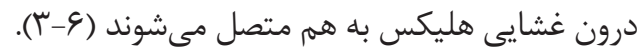

ليگاندهاى TLR يا الخوهاى مولكولى مربوط به هاتوزثنها PAMPS مى توانند بر اساس تركيب شيميايى دستهبندى شوند:

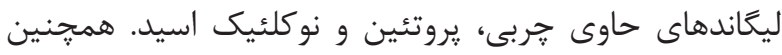

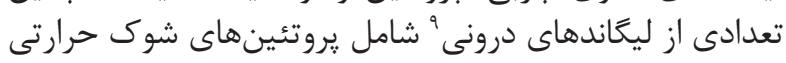

\begin{tabular}{|c|c|c|}
\hline PAMPs & TLRs & 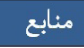 \\
\hline لييو يروتئينهاى باكتريايى، لييو ييتيدها & 1.7 .9 & 1. \\
\hline ليو بلى ساكاريد & t & $\Lambda$ \\
\hline RNA دو رشتداى & $r$ & 11.14 \\
\hline تكى رشتهاى RNA & $r_{6} \wedge$ & ir \\
\hline 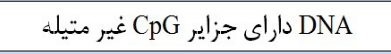 & 9 & If \\
\hline فلازلين & $\Delta$ & is \\
\hline بروفيلين & 11 & r. F \\
\hline
\end{tabular}

${ }^{14}$ Toll-interleukin 1 receptor (TIR) domain containing adaptor protein

${ }^{15}$ TIR-domain-containing adapter-inducing interferon- $\beta$

${ }^{16}$ Toll-like receptor adaptor molecule 1

${ }^{17}$ TIR domain-containing adapter protein

${ }_{18}$ TIR-domain-containing adapter-inducing interferon- $\beta$

${ }^{19}$ Nuclear factor kappa-light-chain-enhancer of activated Bcells

${ }^{20}$ Activator protein 1

${ }^{21}$ Tumor necrosis factor alpha

${ }^{22}$ Interferon regulatory factor

${ }^{23}$ Regulated on activation, normal $\mathrm{T}$ cell expressed and secreted

${ }^{24}$ Chemokine (c-c motif) ligand 5 


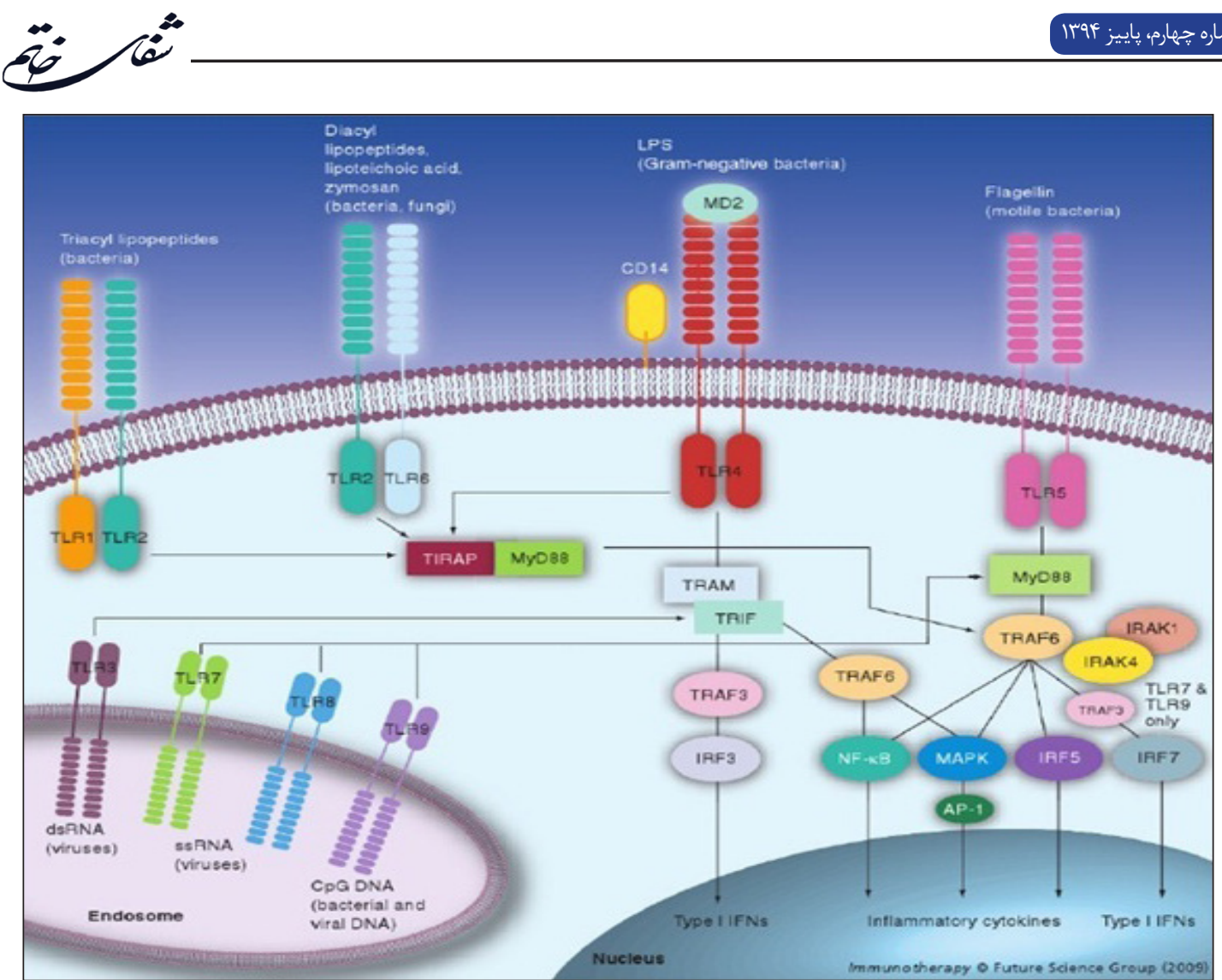

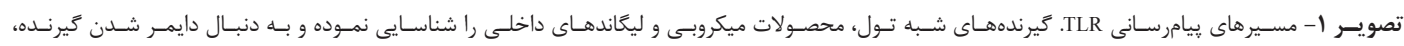

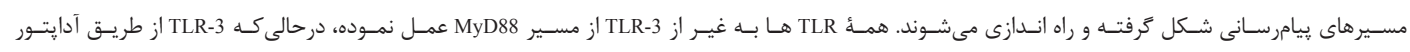

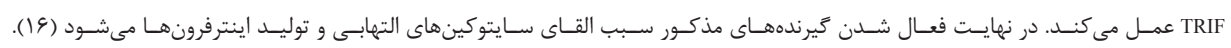

از طريق مسير اتوفازى، اندوزومها را هدف قرار دهند (بار آ).

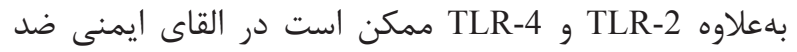

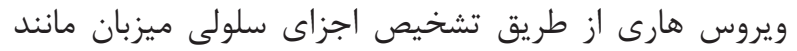

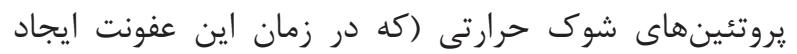

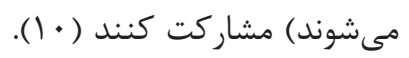

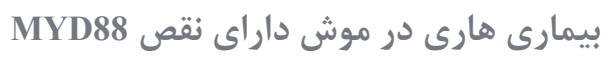

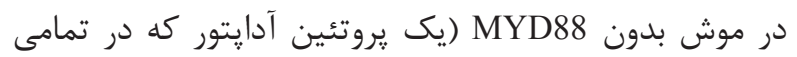
مسيرهاى بِيامرسانى گيرندهها بجز

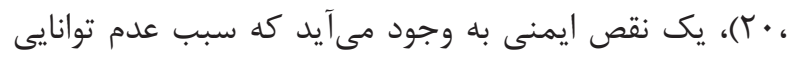

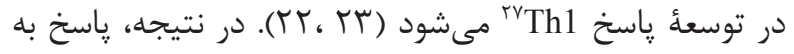

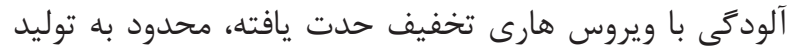

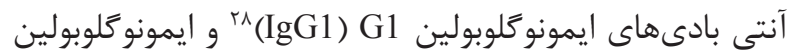
(IgG2b) G2b

موش فاقد MyD88، به دنبال عفونت داخل مغزى با واكسن ضriGAS

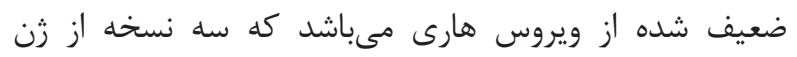

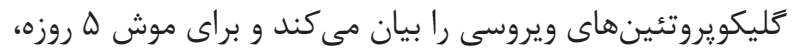

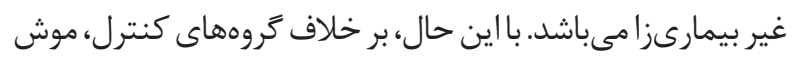

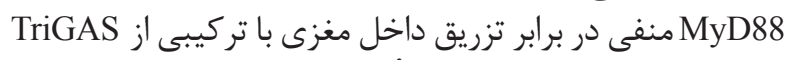

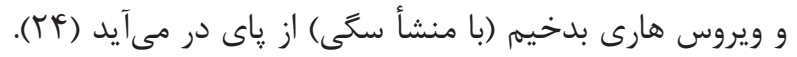

${ }^{25}$ Cell line

${ }^{26}$ Negri bodies

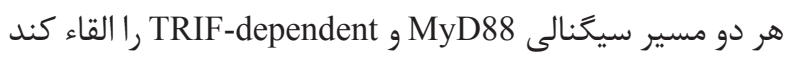
(تصوير (V، II-(I)

نقش كيرندهاى شبه تول در عفونتزايى ويروس هارى به به

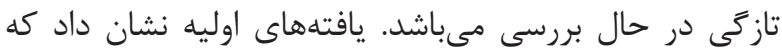

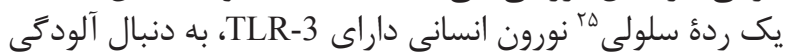

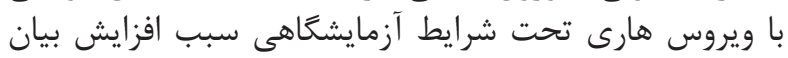

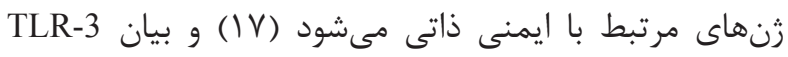

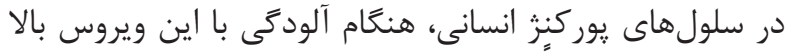

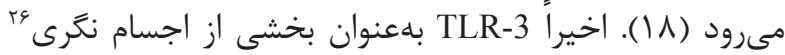

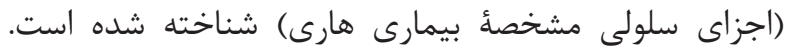

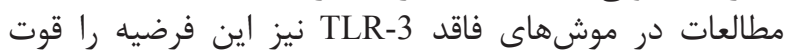

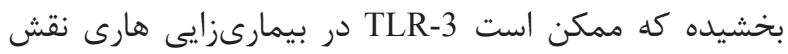

داشته باشد (19) - 19.

از منظر القاء ايمنى محافظتى ضد ويروسى، بعيد است كه

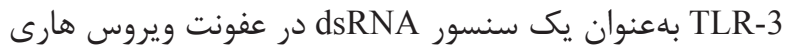

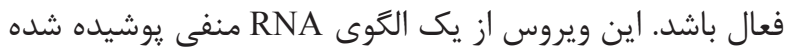

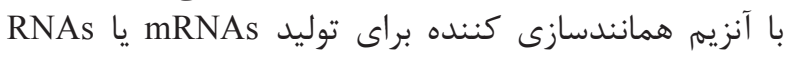

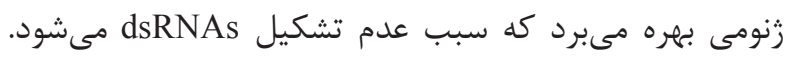

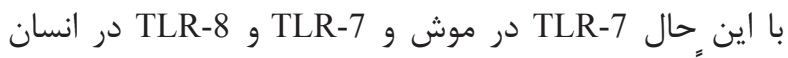

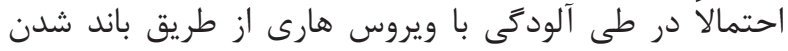

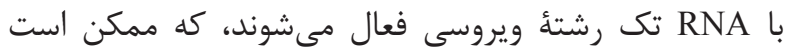

${ }^{27} \mathrm{~T}$ helper cells 1

${ }^{28}$ Immunoglobulin G1 
مقايسه قرار كرفت. نتايج نشان داد، ظهور پِاسخ خنثىسازى

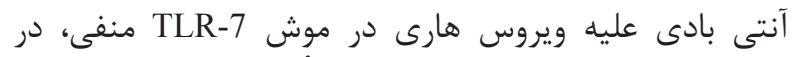
مقايسه با موشهاى كنتر على نرمال به تأخير افتاد.

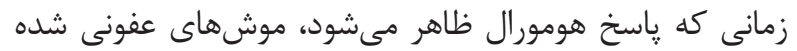

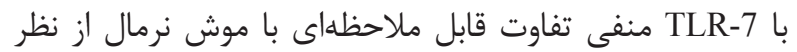

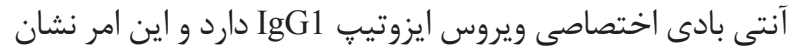

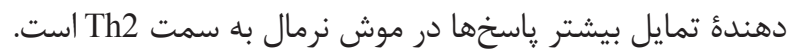

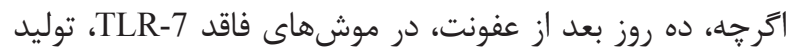

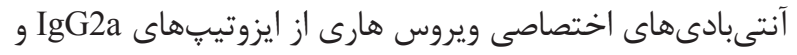

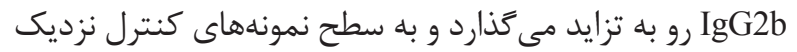

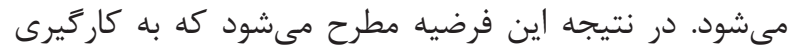

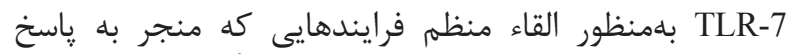

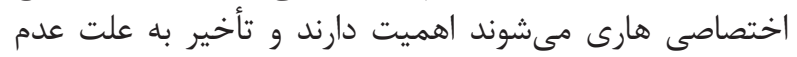

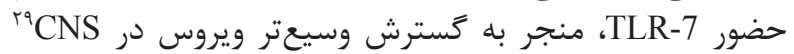

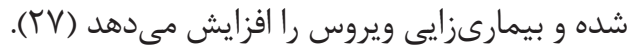
مشار كت ييامر سانى TLR-7 براى كنتر ل يخش ويروس هارى در CNS و پاكسازى از بافتهاى سيستم اعصاب مركزى هدف اولئ ياسخهاى ايمنى -درمانى اختصاصى عليه ويروس

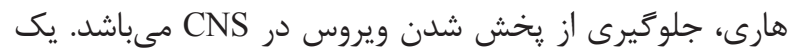

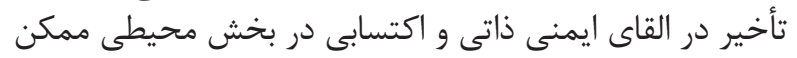

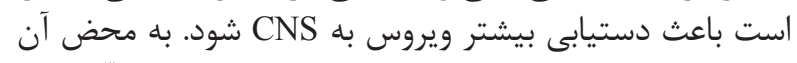

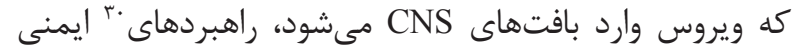

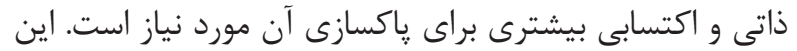

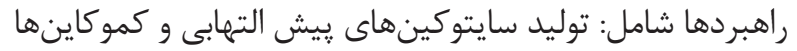

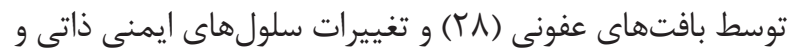

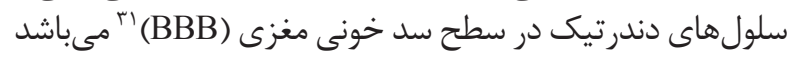

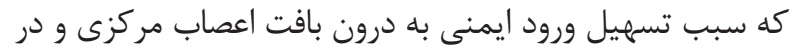

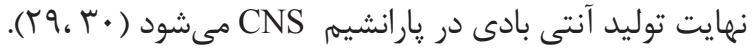

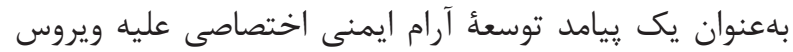

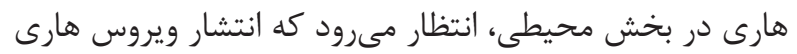

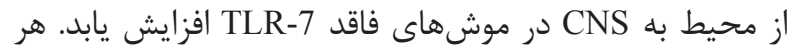

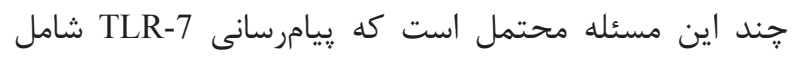

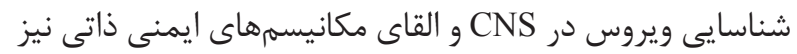

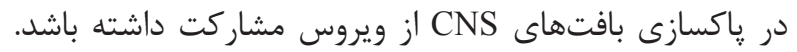

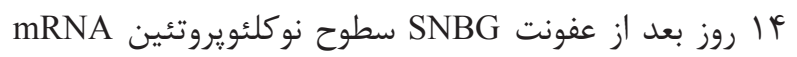

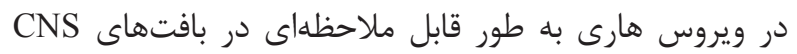

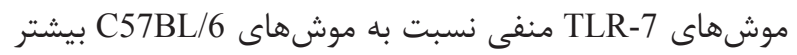

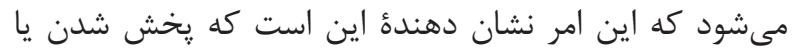

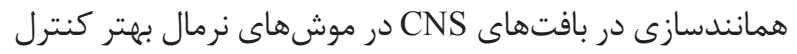

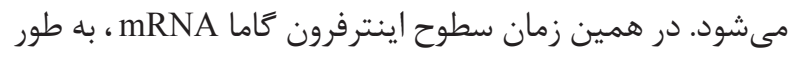

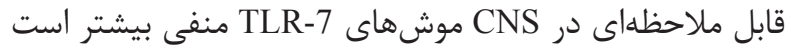

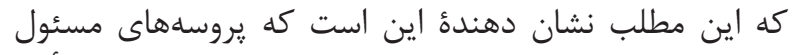

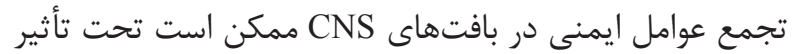

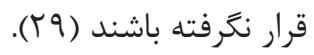

براى بررسى اين كه آيا كاهش توانايى پاكسازى ويروس در برابر

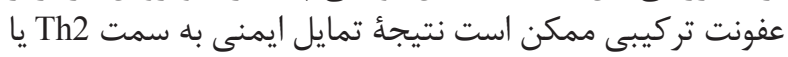

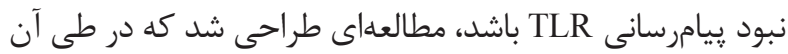

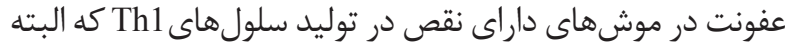

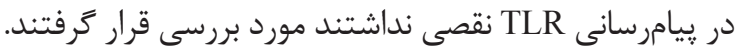

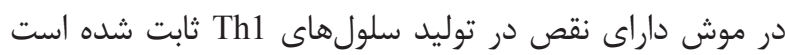

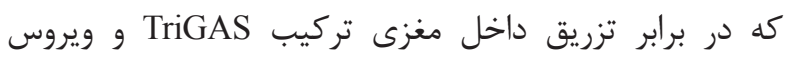

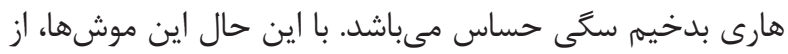

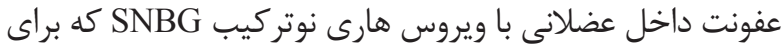

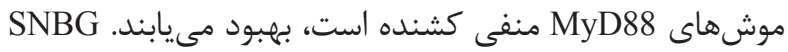

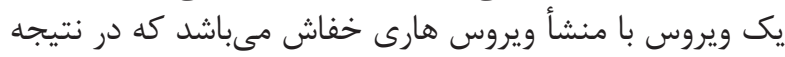

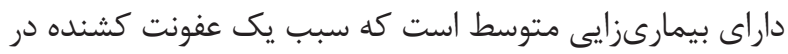

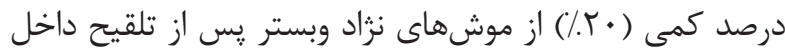

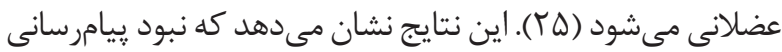

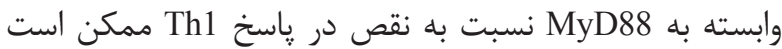
باعث عوارض شديدتر ميزبان در برابر ويروس هارى شود. باست نقش TLR 7 در پاسخ ميزبان به عفونت هارى

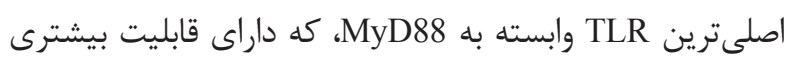
براى تشخيص RNA ويروس هارى مى باشد

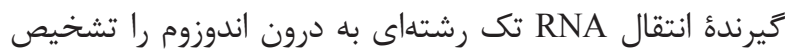

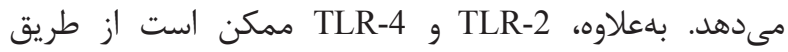

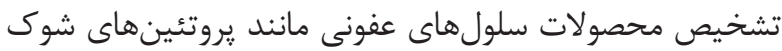

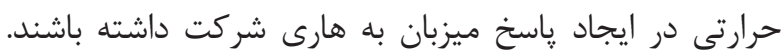

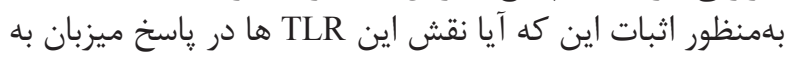

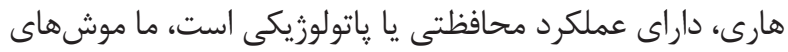

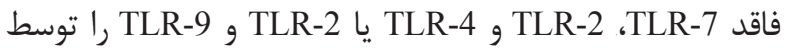

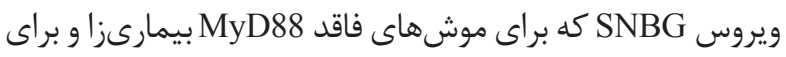

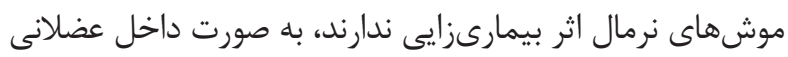

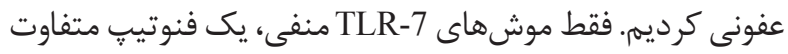

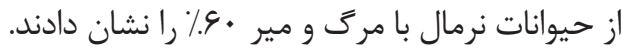

بهعلاوه مشخص كرديد كه موشهاى فاقد كيرنده اينترفرون نوع

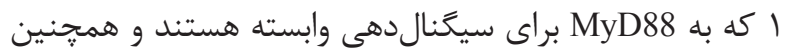

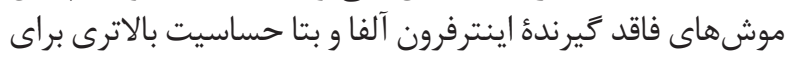

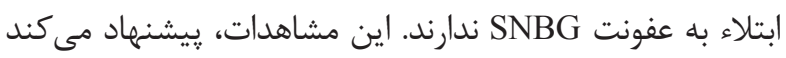

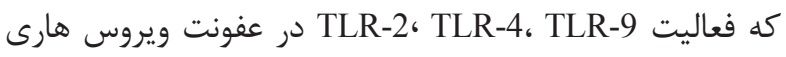

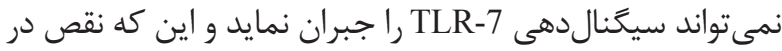

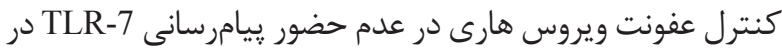

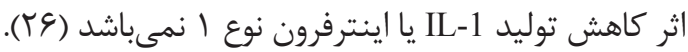

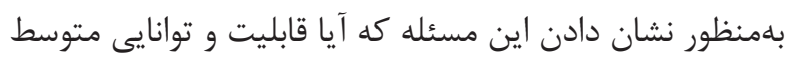

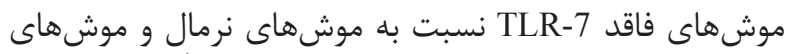

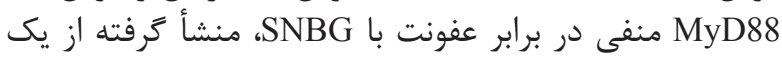

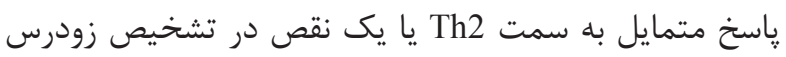

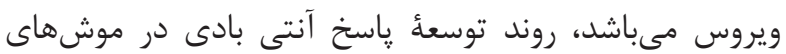

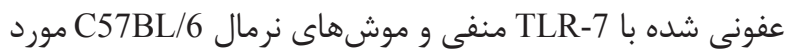

\footnotetext{
${ }^{29}$ Central nervous system

${ }^{30}$ Strategies

${ }^{31}$ Blood-brain barrier
} 


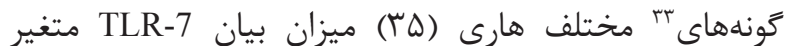

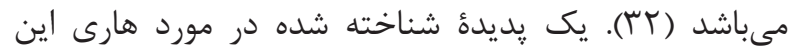

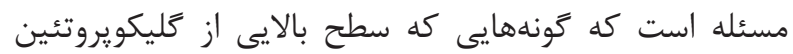

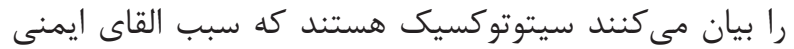

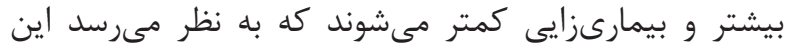

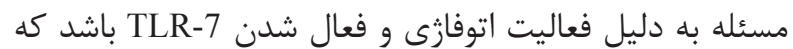

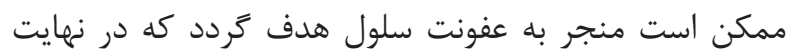

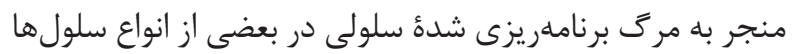

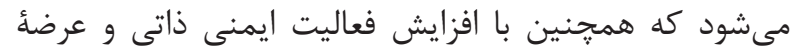
آنتىزن همراه است.

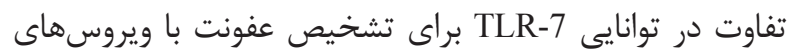

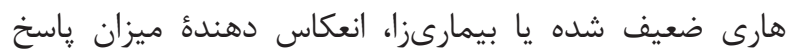

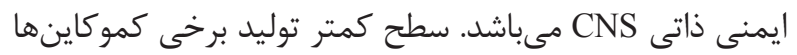

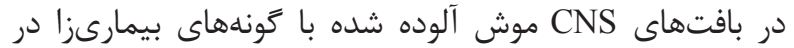

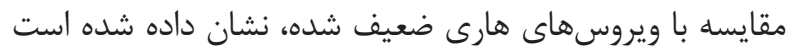

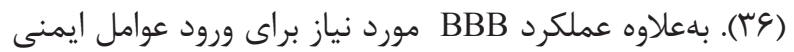

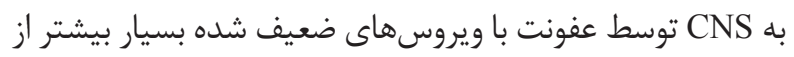

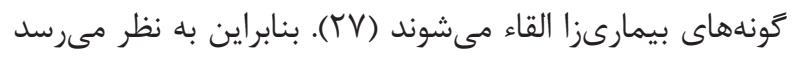

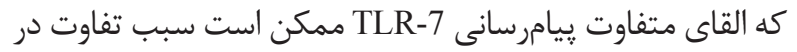

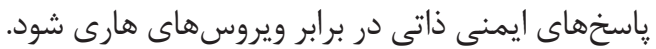

نتيجهَ'يرى

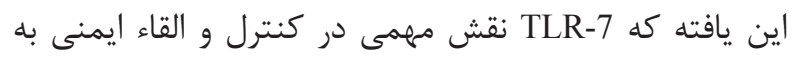

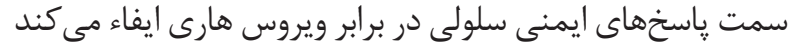

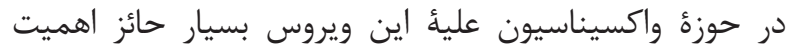

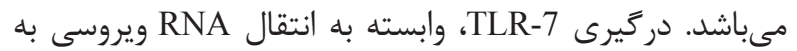

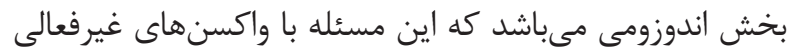

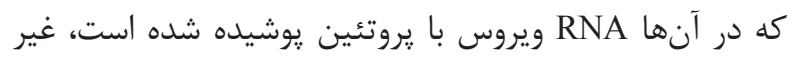

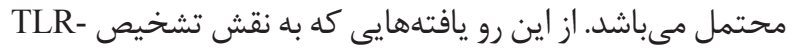

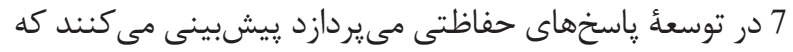

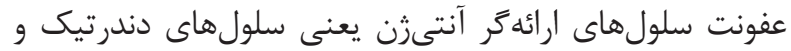

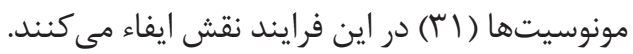

در حقيقت ايمن سازى موشهاى نرمال با ويروس هارى ضعيف

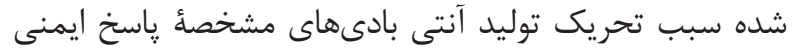

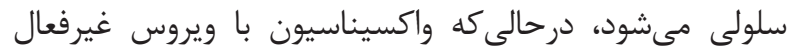

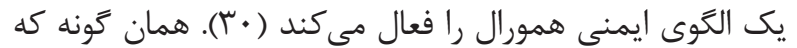

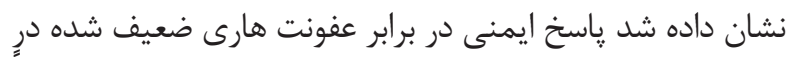

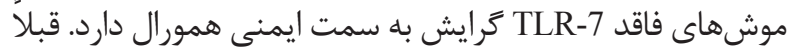

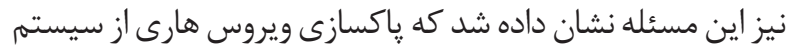

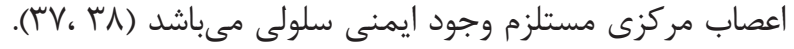
بنابراين مىتوان نتيجه كيرى كرد كه بِيامرسانى

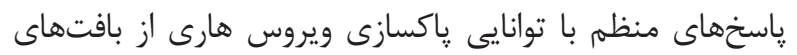
سيستم اعصاب مركزى نقش كليدى ايفاء مىنمايد.
با اين حال، اين احتمال وجود دارد كه نقص يا تأخير در

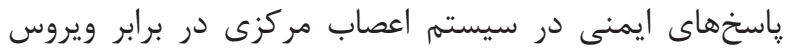

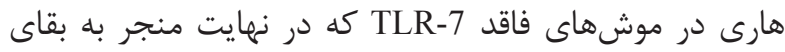
يك سوم موشها در اثر تزريق داخل مغزى بان بات تركيب TriGAS

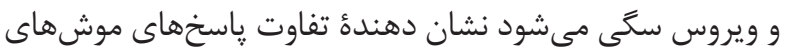

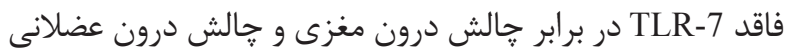

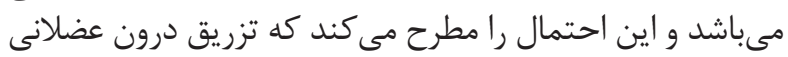
با ويروس واكسن هارى ضعيف شده، اثر آشكارى روى

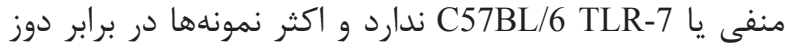
كشنده ويروس سكى تا عأl روز بعد محافظت مىشوند.

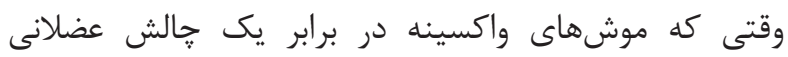

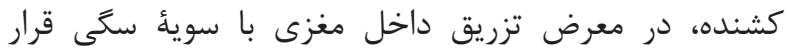

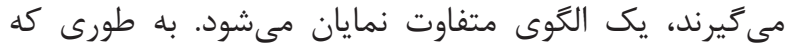

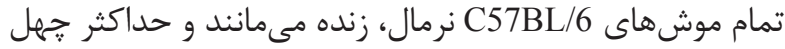

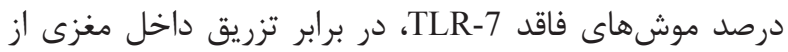

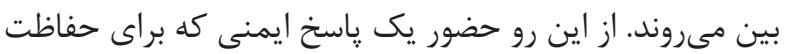

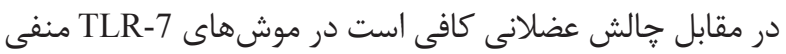

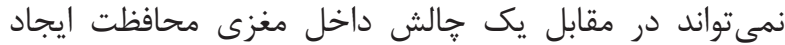

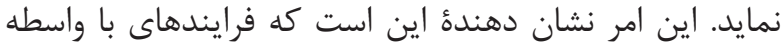

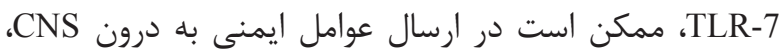

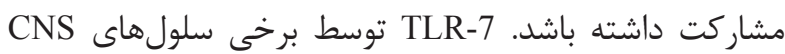

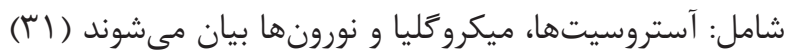

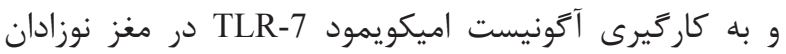
موش، سبب بيان TNF-

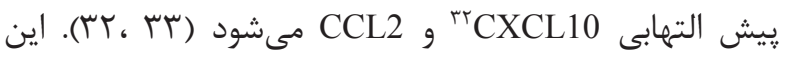

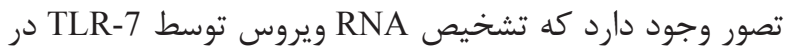

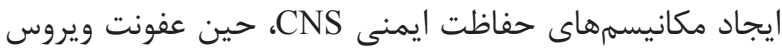

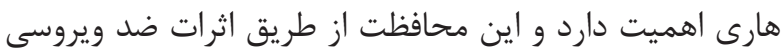

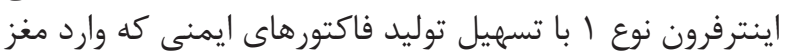

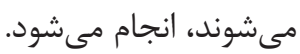

TLR-7 در عدم حضور TLR-7، سويههاى خاصى از هارى، بيمارىزاتر هستند و روشهاى واكسيناسيون هارى كمتر مؤثرند. اين مفهوم

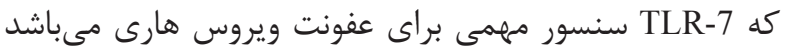

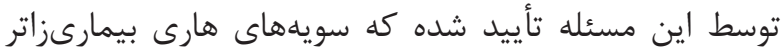

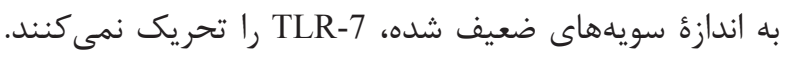

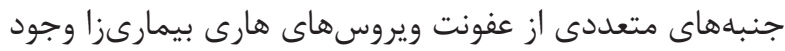

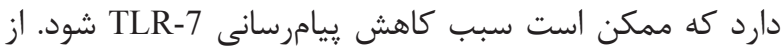

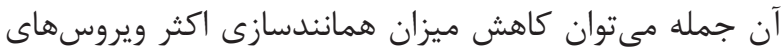

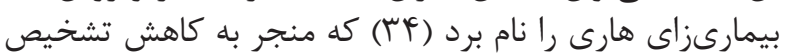
TLR-7

بهعلاوه، بسته به نوع سلولهاى عفونى در CNS توسط 
1. Kanzler H, Barrat FJ, Hessel EM, Coffman RL. Targeting of innate immunity with Toll-like receptor agonists and antagonists. Nat Med. 2007; 13(5): 552-9.

2. Romagne F. Current and future drugs targeting one class of innate immunity receptors: the toll-like receptors. Drug Discov Today. 2007; 12(1-2): 80-7.

3. Rezaei N. Therapeutic targeting of pattern-recognition receptors. Int Immunopharmacol. 2006; 6(6): 863-9.

4. Pandey S, Agrawal DK. Immunobiology of toll-like receptors: emerging trends. Immunol Cell Biol. 2006; 84(4): 333-41.

5. Gearing AJ. Targeting toll-like receptors for drug development: a summary of commercial approaches. Immunol Cell Biol. 2007; 85(6): 490-4.

6. Miyake K. Innate immune sensing of pathogens and danger signals by cell surface toll-like receptors. Semin Immunol. 2007; 19(1): 3-10.

7. Chen K, Huang J, Gong W, Iribarren P, Dunlop NM, Wang JM. Toll-like receptors in inflammation, infection and cancer. Int Immunopharmacol. 2007; 7(10): 1271-85.

8. Mata-Haro V, Cekic C, Martin M, Chilton PM, Casella CR, Mitchell TC. The vaccine adjuvant monophosphoryl lipid A as a TRIF-biased agonist of TLR4. Science. 2007; 316(5831): 1628-32.

9. Sajadian A, Tabarraei A, Soleimanjahi H, Moradi A, Fotouhi F, Gorji A, et al. Comparing the effect of Tolllike receptor agonist adjuvants on the efficiency of the DNA vaccine. Arch Virol. 2014; 159(8): 1951-60.

10. Prosniak M, Hooper DC, Dietzschold B, Koprowski H. Effect of rabies virus infection on gene expression in mouse brain. Proc Natl Acad Sci USA. 2001; 98(5): 2758-63.

11. Kagan JC, Su T, Horng T, Chow A, Akira S, Medzhitov R. TRAM couples endocytosis of tolllike receptor 4 to the induction of interferon-beta. Nat Immunol. 2008; 9(4): 361-8.

12. Ghaemi A, Sajadian A, Khodaie B, LotfiniaA, Lotfinia M, Aghabarari A, et al. Immunomodulatory effect of Toll-like receptor-3 ligand poly I:C on cortical spreading depression. Mol Neurobiol. 2014; 53(1): 143-54.

13. Delgado M, Singh S, DeHaro S, Master S, Ponpuak $\mathrm{M}$, Dinkins $\mathrm{C}$, et al. Autophagy and pattern recognition receptors in innate immunity. Immunol Rev. 2009; 227(1): 189-202.

14. Togha M, Jahanshahi M, Alizadeh L, Jahromi SR, Vakilzadeh G, Alipour B, et al. Rapamycin augments immunomodulatory properties of bone marrow-derived mesenchymal stem cells in experimental autoimmune encephalomyelitis. Mol Neurobiol. 2016; 12: 1-13.

15. Gableh F, Saeedi M, Hamdi K, Gorji A, Ghaemi A. Combination of the Toll like receptor agonists and $\alpha$-galactosylceramide as an efficient adjuvant for cancer vaccine. J Biomed Sci. 2016; 25(23):16. doi: 10.1186/ s12929-016-0238-3.

16. Adams S. Toll-like receptor agonists in cancer therapy. Immunotherapy. 2009; 1(6): 949-64.

17. Menager P, Roux P, Megret F, Bourgeois JP, Le Sourd AM, Danckaert A, et al. Toll-like receptor 3 (TLR3) plays a major role in the formation of rabies virus Negri bodies. PLoSPathog. 2009; 5(2): 5:e1000315. doi: 10.1371/journal.ppat.1000315.

18. Jackson AC, Rossiter JP, Lafon M. Expression of Tolllike receptor 3 in the human cerebellar cortex in rabies, herpes simplex encephalitis, and other neurological diseases. J Neurovirol. 2006; 12(3): 229-34.

19. Lahaye X, Vidy A, Pomier C, Obiang L, Harper F, Gaudin Y, et al. Functional characterization of Negri bodies (NBs) in rabies virus-infected cells: evidence that NBs are sites of viral transcription and replication. J Virol. 2009; 83(16): 7948-58.

20. Akira S, Takeda K. Toll-like receptor signalling. Nat Rev Immunol. 2004; 4: 499-511.

21. Kopp E, Medzhitov R. Recognition of microbial infection by Toll-like receptors. Curr Opin Immunol. 2003; 15(4): 396-401.

22. Akira S. The role of IL-18 in innate immunity. Curr Opin Immunol. 2000; 12(1): 59-63.

23. Scanga CA, Bafica A, Feng CG, Cheever AW, Hieny S, Sher A. MyD88- deficient mice display a profound loss in resistance to mycobacterium tuberculosis associated with partially impaired Th1 cytokine and nitric oxide synthase 2 expression. Infect Immun. 2004; 72(4): 2400-4.

24. Faber M, Li J, Kean RB, Hooper DC, Alugupalli KR, Dietzschold B. Effective preexposure and postexposure 


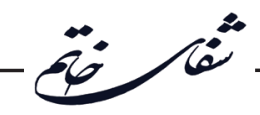

prophylaxis of rabies with a highly attenuated recombinant rabies virus. Proc Natl Acad Sci USA. 2009. 106(27): 11300-5.

25. Pulmanausahakul R, Li J, Schnell MJ, Dietzschold B. The glycoprotein and the matrix protein of rabies virus affect pathogenicity by regulating viral replication and facilitating cell-to-cell spread. J Virol. 2008; 82(5): 2330-8.

26. Detrick B, Hamilton RG, Folds JD. Manual of molecular and clinical laboratory immunology. $7^{\text {th }}$ ed. Amer Society for Microbiology. 2006. P. 791-7.

27. Roy A, Phares TW, Koprowski H, Hooper DC. Failure to open the blood-brain barrier and deliver immune effectors to central nervous system tissues leads to the lethal outcome of silver-haired bat rabies virus infection. J Virol. 2007; 81(3): 1110-8.

28. Phares TW, Kean RB, Mikheeva T, Hooper DC. Regional differences in blood-brain barrier permeability changes and inflammation in the apathogenic clearanceof virus from the central nervous system. J Immunol. 2006; 176(12): 7666-75.

29. Hooper DC, Phares TW, Fabis MJ, Roy A. The production of antibody by invading $\mathrm{B}$ cells is required for the clearance of rabies virus from the central nervous system. PLoS Negl Trop Dis. 2009; 3(10):e535. doi: 10.1371/journal.pntd.0000535.

30. Hooper DC, Roy A, Barkhouse DA, Li J, Kean RB. Rabies virus clearance from the central nervous system. Adv Virus Res. 2011; 79: 55-71.

31. Butchi NB, Pourciau S, Du M, Morgan TW, Peterson KE. Analysis of the neuroinflammatory response to TLR7 stimulation in the brain: comparison of multiple
TLR7 and/or TLR8 agonists. J Immunol. 2008; 180: 7604-12.

32. Butchi NB, Du M, Peterson KE. Interactions between TLR7 and TLR9 agonists and receptors regulate innate immune responses by astrocytes and microglia. Glia. 2010; 58(6): 650-64.

33. Li J, McGettigan JP, Faber M, Schnell MJ, Dietzschold B. Infection of monocytes or immature dendritic cells (DCs) with an attenuated rabies virus results in DC maturation and a strong activation of the NFkappaB signaling pathway. Vaccine. 2008; 26(3): 419-26.

34. Yan X, Prosniak M, Curtis MT, Weiss ML, Faber M, Dietzschold B, et al. Silver-haired bat rabies virus variant does not induce apoptosis in the brain of experimentally infected mice. J Neurovirol. 2001; 7(6): 518-27.

35. Morimoto K, Patel M, Corisdeo S, Hooper DC, $\mathrm{Fu} \mathrm{ZF}$, Rupprecht CE, et al. Characterization of a unique variant of bat rabies virus responsible for newly emerging human cases in North America. Proc Natl Acad Sci USA. 1996; 93(11): 5653-8.

36. Kuang Y, Lackay SN, Zhao L, Fu ZF. Role of chemokines in the enhancement of BBB permeability and inflammatory infiltration after rabies virus infection. Virus Res. 2009; 144(1-2): 18-26.

37. Heil F, Hemmi H, Hochrein H, Ampenberger F, irschning C, Akira S, et al. Species-specific recognition of single-stranded RNA via toll-like receptor 7 and 8 . Science. 2004; 303(5663): 1526-9.

38. Hooper DC, Morimoto K, Bette M, Weihe E, Koprowski H, Dietzschold B. Collaboration of antibody and inflammation in clearance of rabies virus from the central nervous system. J Virol. 1998; 72: 3711-9. 